\title{
Anatomy of the Pulmonary Veins in Patients with Atrial Fibrillation and Effects of Segmental Ostial Ablation Analyzed by Computed Tomography
}

\author{
CHRISTOPH SCHARF, M.D., MICHAEL SNEIDER, M.D., ${ }^{*}$ IAN CASE, R.T. (R), ${ }^{*}$ \\ AMAN CHUGH, M.D., STEVE W.K. LAI, M.D., FRANK PELOSI, JR., M.D., \\ BRADLEY P. KNIGHT, M.D., ELLA KAZEROONI, M.D., ${ }^{*}$ FRED MORADY, M.D., \\ and HAKAN ORAL, M.D.
}

\begin{abstract}
From the Division of Cardiology, Department of Internal Medicine and *Department of Radiology, University of Michigan, Ann Arbor, Michigan, USA
\end{abstract}

\begin{abstract}
Pulmonary Vein Anatomy. Introduction: The anatomic arrangement of pulmonary veins (PVs) is variable. No prior studies have quantitatively analyzed the effects of segmental ostial ablation on the PVs. The aim of this study was to determine the effect of segmental ostial radiofrequency ablation on PV anatomy in patients with atrial fibrillation (AF).

Methods and Results: Three-dimensional models of the PVs were constructed from computed tomographic (CT) scans in 58 patients with AF undergoing segmental ostial ablation to isolate the PVs and in 10 control subjects without a history of AF. CT scans were repeated approximately 4 months later. PV and left atrial dimensions were measured with digital calipers. Four separate PV ostia were present in 47 subjects; 3 ostia were present in 2 subjects; and 5 ostia were present in 9 subjects. The superior PVs had a larger ostium than the inferior PVs. Patients with AF had a larger left atrial area between the PV ostia and larger ostial diameters than the controls. Segmental ostial ablation resulted in a $1.5 \pm 3.2 \mathrm{~mm}$ narrowing of the ostial diameter. A $28 \%$ to $61 \%$ focal stenosis was present $7.6 \pm 2.2 \mathrm{~mm}$ from the ostium in $3 \%$ of 128 isolated PVs. There were no instances of symptomatic PV stenosis during a mean follow-up of $245 \pm 105$ days.

Conclusion: CT of the PVs allows identification of anatomic variants prior to catheter ablation procedures. Segmental ostial ablation results in a significant but small reduction in ostial diameter. Focal stenosis occurs infrequently and is attributable to delivery of radiofrequency energy within the PV. ( $J$ Cardiovasc Electrophysiol, Vol. 14, pp. 150-155, February 2003)
\end{abstract}

atrial fibrillation, pulmonary vein, computed tomography, catheter ablation

\section{Introduction}

The pulmonary veins play an important role in triggering or generating atrial fibrillation, and their anatomy may be highly variable. ${ }^{1-4}$ Whether there are differences in the pulmonary veins between patients with paroxysmal and persistent atrial fibrillation is unknown. Segmental ostial ablation of the pulmonary veins has been demonstrated to be effective in preventing recurrences of atrial fibrillation. ${ }^{5,6}$ However, radiofrequency catheter ablation in the vicinity of the ostia is associated with a risk of pulmonary vein stenosis. ${ }^{7-11} \mathrm{No}$ prior studies have systematically quantified the effects of segmental ostial ablation on the pulmonary veins.

In the present study, computed tomography (CT) was used to visualize the pulmonary veins in three dimensions. The aim of the study was twofold: (1) to compare the anatomy of the pulmonary veins in patients with paroxysmal, persistent, or

Supported in part by the Ellen and Robert Thompson Atrial Fibrillation Research Fund. Dr. Scharf was supported by the Swiss National Science Foundation.

Address for correspondence: Hakan Oral, M.D., Division of Cardiology, University of Michigan, TC B1 140, 1500 E. Medical Center Drive, Ann Arbor, MI 48109-0311. Fax: 734-936-7026; E-mail: oralh@umich.edu

Manuscript received 9 October 2002; Accepted for publication 21 November 2002. no atrial fibrillation; and (2) to prospectively determine the effects of segmental ostial ablation on the pulmonary veins.

\section{Methods}

\section{Study Subjects}

The subjects of this study were 58 consecutive patients with atrial fibrillation (50 men and 8 women; mean age $52 \pm$ 8 years) who underwent CT before and after segmental ostial ablation of the pulmonary veins, and 10 control subjects who had no history of atrial fibrillation. Atrial fibrillation was paroxysmal in 45 patients and persistent in 13 patients. Atrial fibrillation was considered persistent when it lasted $>30$ days and required cardioversion for termination. Atrial fibrillation had been first diagnosed $8 \pm 7$ years before ablation. Structural heart disease was present in 11 (19\%) of the 58 patients with atrial fibrillation: coronary artery disease in $4(7 \%)$, valvular heart disease in $2(3 \%)$, and nonischemic cardiomyopathy in $5(9 \%)$. Mean left ventricular ejection fraction was $0.53 \pm 0.05$, and mean left atrial diameter was $41 \pm 5 \mathrm{~mm}$. Twenty-seven of the patients with atrial fibrillation also had been subjects of a previous study. ${ }^{6}$

The control subjects consisted of 10 patients (mean age $44 \pm 18$ years) who underwent CT because of suspected pulmonary embolism (3) or pulmonary disease (7). None of the control subjects had a history of atrial fibrillation. Two (20\%) of the control subjects had coronary artery disease, and 
the other 8 did not have structural heart disease. The control subjects did not differ significantly from the patients with atrial fibrillation with regard to clinical characteristics.

\section{Radiofrequency Ablation}

The techniques used to isolate the pulmonary veins by segmental ostial ablation were described previously. ${ }^{6}$ Informed written consent was obtained from all patients. Transseptal catheterization was performed, and two catheters were advanced into the left atrium: a deflectable, decapolar catheter with a distal ring configuration (Lasso $^{\mathrm{TM}}$ catheter, Biosense Webster, Diamond Bar, CA, USA); and a deflectable, quadripolar 7-French catheter with 2-5-2 $\mathrm{mm}$ interelectrode spacing and a 4-mm distal electrode with an embedded thermistor (EP Technologies, Mountain View, CA, USA). The pulmonary veins were visualized by selective venograms. The Lasso catheter was positioned in the pulmonary veins, within $5 \mathrm{~mm}$ of the ostium. Segmental ostial ablation guided by pulmonary vein potentials was performed with conventional applications of radiofrequency energy delivered proximal to the Lasso catheter, at the veno-atrial junction. The target electrode-tissue interface temperature was $52^{\circ} \mathrm{C}$, and power was limited to 30 to $35 \mathrm{~W}$. Energy applications were 30 to 45 seconds in duration. The left superior, left inferior, and right superior pulmonary veins were isolated in all patients; the right inferior pulmonary vein also was isolated in 16 patients. The patients underwent anticoagulation with heparin during the procedure and with warfarin for at least 1 month after the procedure. Catheter ablation was repeated $89 \pm 52$ days after the first procedure in $8(14 \%)$ of the 58 patients who had recurrent episodes of atrial fibrillation during follow-up.

\section{Computed Tomography}

Contrast-enhanced CT of the chest was performed 1 to 4 weeks before and $111 \pm 54$ days after the first catheter ablation procedure. In 8 patients who underwent a repeat ablation procedure, follow-up CT was performed $93 \pm 84$ days after the second procedure.

CT was performed with a QX/i four-row multidetector CT scanner (GE LightSpeed, GE Medical Imaging, Waukesha, WI, USA). Non-ionic intravenous contrast material $(150 \mathrm{~mL}$ of Omnipaque 300, Nycomed, Inc., Princeton, NJ, USA) was administered through an antecubital vein with a power injector at a rate of $4 \mathrm{~mL} / \mathrm{sec}$. Scanning was initiated 30 seconds after the onset of contrast injection. A collimation of $1.25 \mathrm{~mm}$ was used and reconstruction was done with a $0.6-\mathrm{mm}$ interval. The 7.5 high-speed (HS) pitch mode was used for all scans, and scanning was performed from the lung bases to the apices during a single breath-hold. The resolution of the CT scans was $1.25 \mathrm{~mm}$.

\section{Construction of Three-Dimensional Pulmonary Vein Models}

CT data were processed using volume analysis software (GE Advantages Windows workstation, GE Medical Systems). Three-dimensional models were constructed to exclude surrounding structures such as the aorta, vertebral column, ribs, lung parenchyma, and peripheral pulmonary arteries. Partial volume filters of 80 to 100 Hounsfield units were used for contrast enhancement. To prevent overlap by proximal segments of the pulmonary arteries, the pulmonary veins were viewed from the dorsocranial aspect, with right or left posterior oblique angulation (Fig. 1).

The pulmonary vein ostium was defined by the intersection of tangents extending from the surface of the pulmonary vein and the wall of the adjacent left atrium (Fig. 2). Pulmonary vein diameters were measured from three-dimensional reconstructions. The three-dimensional image was rotated in space such that the pulmonary vein and its ostium were visualized completely without any interference from overlying structures and without any foreshortening of the pulmonary vein. The ostial diameter was measured with digital calipers as the maximum distance between two ostial points in the same plane and in at least two orthogonal projections (Fig. 2).

Each pulmonary vein was inspected in multiple projections to determine whether there was any focal narrowing. Focal narrowing was defined as an abrupt change in luminal diameter (Fig. 3). If a focal narrowing was identified, the distance from the site of maximal narrowing to the pulmonary vein ostium was measured.

Because of motion artifact, accurate reconstruction of the anterior wall of the left atrium often was not possible; therefore, left atrial dimensions and volume could not be determined. For this reason, the surface area of the posterior left atrium was used as a surrogate for left atrial size. The posterior left atrial area was defined as the area bounded by lines connecting the ostia of the pulmonary veins (Fig. 2).

To assess the reproducibility of measurements over time, the distance from the pulmonary vein ostium to its first branch also was measured.

\section{Reproducibility of Measurements}

All pulmonary vein measurements were made in duplicate on separate days. Mean intra-observer variation between duplicate measurements of ostial diameter was $0.5 \pm$ $1.8 \mathrm{~mm}(4 \% \pm 11 \%)$. Because the resolution of the scans was $1.25 \mathrm{~mm}$ and digital measurements always were rounded to include the next pixel, $10 \%$ variability between duplicate measurements was considered acceptable. If the variability between duplicate measurements was $>10 \%$, the scans were reviewed by three observers and a final measurement was determined by consensus.

\section{Statistical Analysis}

Continuous variables are expressed as mean \pm SD. Continuous variables were compared using either Student's $t$-test or paired $t$-test, as appropriate. Differences among groups were determined by analysis of variance, and post hoc analyses were performed with the Newman-Keuls test. Relationships between continuous variables were examined with Pearson correlation matrices. Multivariate linear regression analysis was performed to determine the predictors of pulmonary vein size. $\mathrm{P}<0.05$ was considered statistically significant.

\section{Results}

\section{Pulmonary Vein Anatomy}

Among the 58 patients with atrial fibrillation, there were 4 separate pulmonary vein ostia in 47 patients (81\%), 3 separate ostia (due to a common left pulmonary vein) in 2 patients 


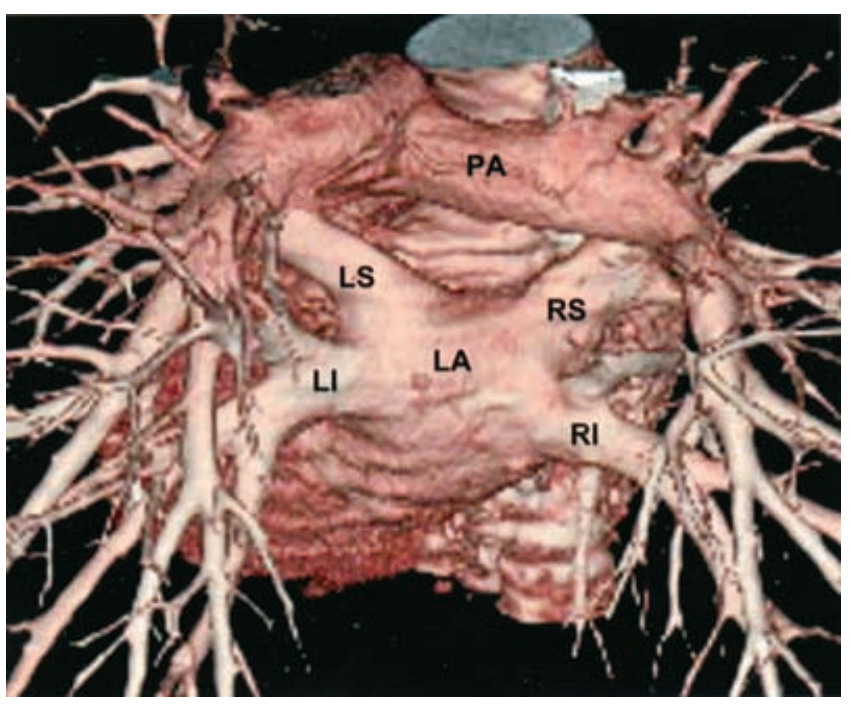

Figure 1. Computed tomographic scan with three-dimensional reconstruction of the pulmonary veins and posterior left atrium $(L A) . L I=$ left inferior pulmonary vein; $L S=$ left superior pulmonary vein; $P A=$ pulmonary artery; $R I=$ right inferior pulmonary vein; $R S=$ right superior pulmonary vein

(3\%), and 5 separate ostia (due to a separate right middle pulmonary vein) in 9 patients (16\%).

Relative to the ostia of the superior pulmonary veins, the ostia of the inferior pulmonary veins were more posterior and medial. The superior pulmonary veins had a longer trunk than the inferior pulmonary veins $(21.6 \pm 7.5 \mathrm{~mm}$ vs $14.0 \pm$ $6.2 \mathrm{~mm} ; \mathrm{P}<0.001)$. The left-sided pulmonary veins had a longer trunk than the right-sided pulmonary veins $(21.7 \pm$ $7.1 \mathrm{~mm}$ vs $13.6 \pm 6.3 \mathrm{~mm} ; \mathrm{P}<0.001)$.

\section{Size of the Pulmonary Vein Ostia}

In patients with atrial fibrillation, the mean ostial diameter of the pulmonary veins (excluding the common left pulmonary veins) was $18.0 \pm 3.7 \mathrm{~mm}$. Mean ostial diameter of the superior pulmonary veins was larger than that of the inferior pulmonary veins $(19.7 \pm 3.6 \mathrm{~mm}$ vs $17.0 \pm 2.0 \mathrm{~mm}$; $\mathrm{P}<0.001)$. There was no significant difference in ostial diameter between left-sided and right-sided pulmonary veins.

The mean ostial diameter of the common left pulmonary veins was significantly larger than that of the other pulmonary veins $(32.5 \pm 0.5 \mathrm{~mm}$ vs $18.0 \pm 3.7 \mathrm{~mm} ; \mathrm{P}<0.001)$. Mean ostial diameter of the right middle pulmonary veins $(9.9 \pm$ $1.9 \mathrm{~mm}$ ) was significantly smaller than the ostial diameter of the other pulmonary veins $(\mathrm{P}<0.001)$.

The mean ostial diameters in patients with paroxysmal atrial fibrillation and persistent atrial fibrillation were larger than those in control subjects $(17.9 \pm 3.7 \mathrm{~mm}$ and $18.5 \pm$ $3.9 \mathrm{~mm}$ vs $14.8 \pm 4.2 \mathrm{~mm}$; $\mathrm{P}<0.001$; Fig. 4). The mean ostial diameter did not differ significantly between patients with paroxysmal and persistent atrial fibrillation $(\mathrm{P}=0.3$; Fig. 4).

\section{Posterior Left Atrial Area}

Patients with persistent atrial fibrillation had a larger posterior left atrial area than patients with paroxysmal atrial fibrillation $\left(1,817 \pm 302 \mathrm{~mm}^{2}\right.$ vs $1,514 \pm 258 \mathrm{~mm}^{2} ; \mathrm{P}<0.001$; Fig. 5). However, the posterior left atrial area was not significantly different between patients with paroxysmal atrial

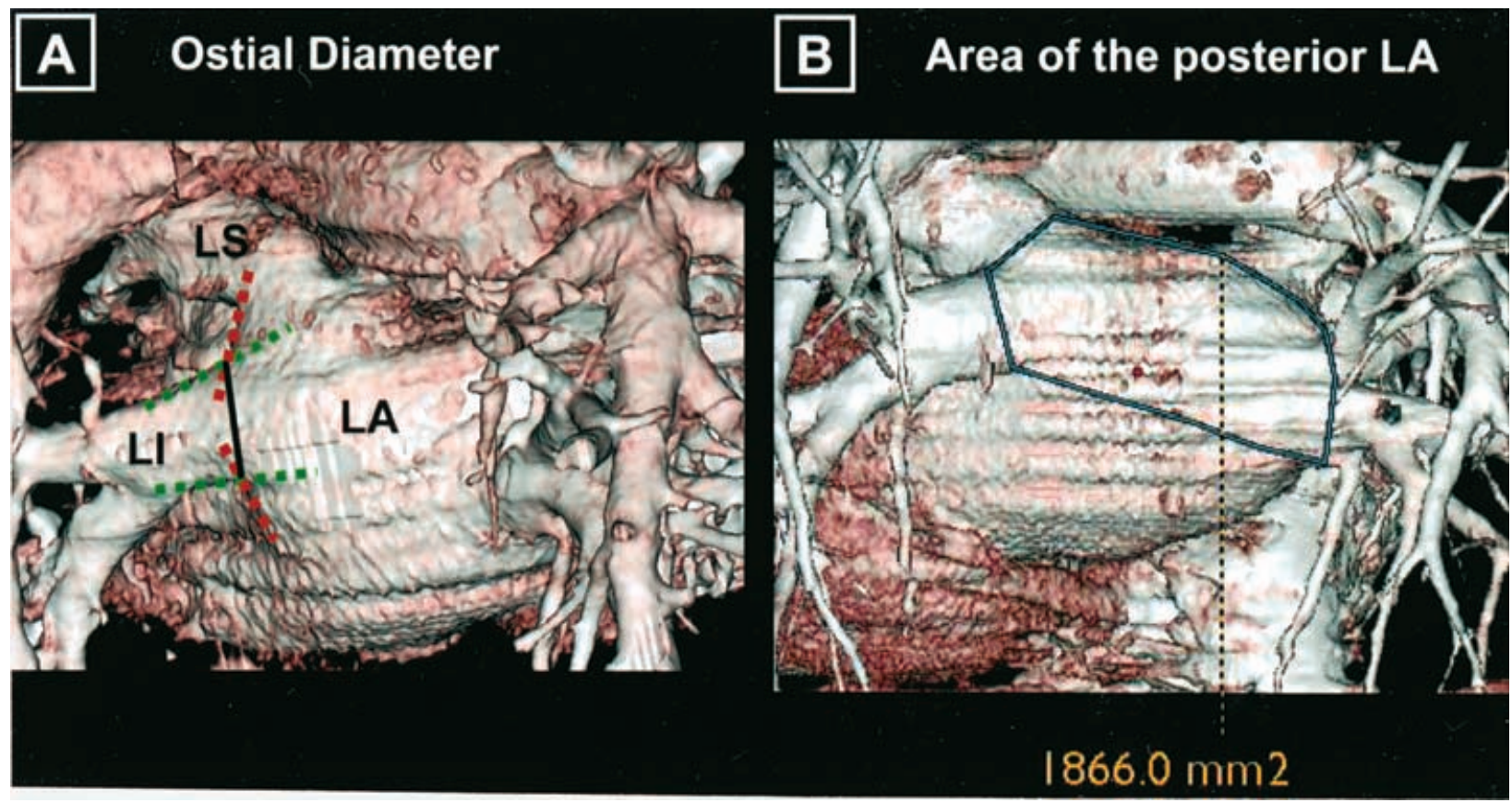

Figure 2. Measurement techniques. A: To measure the ostial diameter, the three-dimensional reconstruction was rotated in space such that the veno-atrial junction was clearly identified, without any foreshortening of the vein. The pulmonary vein ostium was defined by the intersection of tangents extending from the outer surface of the pulmonary vein (green dashed line) and the wall of the adjacent left atrium (red dashed line). The ostial diameter (black line) was measured with digital calipers as the maximum distance between two ostial points in the same plane and in at least two orthogonal projections. B: The posterior left atrial area was defined as the area bounded by lines connecting the pulmonary vein ostia. $L A=$ left atrium; $L I=l e f t$ inferior pulmonary vein; $L S=$ left superior pulmonary vein. 


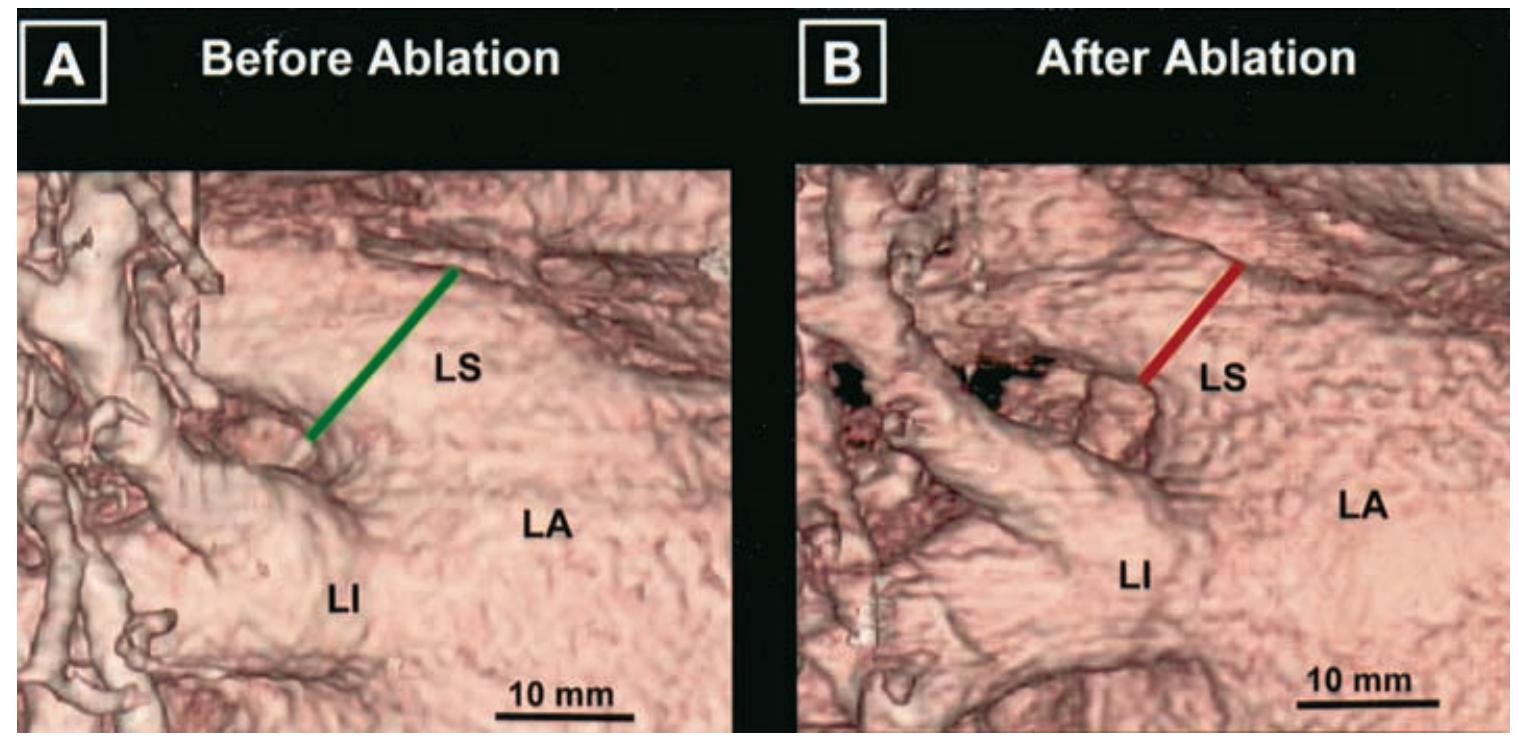

Figure 3. Example of focal narrowing of the left superior and inferior pulmonary veins after segmental ostial ablation. There is a $40 \%$ reduction in the diameter of the left superior pulmonary vein. The focal narrowing is $8 \mathrm{~mm}$ from the ostium of the left superior pulmonary vein, indicating that radiofrequency energy probably was applied inside the vein instead of at the ostium. LA = left atrium; LI = left inferior pulmonary vein; LS = left superior pulmonary vein.

fibrillation and the control subjects $\left(1,514 \pm 258 \mathrm{~mm}^{2}\right.$ vs $\left.1,386 \pm 169 \mathrm{~mm}^{2} ; \mathrm{P}=0.2\right)$.

\section{Multivariate Predictors of Ostial Size}

There was a positive correlation between ostial diameter and posterior left atrial area $(\mathrm{r}=0.21, \mathrm{P}<0.001)$. By multivariate analysis of several variables (age, gender, area of the posterior left atrium, history of atrial fibrillation, presence of structural heart disease), history of atrial fibrillation and posterior left atrial area were the only independent predictors of ostial diameter of the pulmonary veins $(\mathrm{P}<0.01)$.

\section{Pulmonary Vein Isolation}

Among the 192 pulmonary veins targeted for isolation in the 58 patients with atrial fibrillation, 187 (97\%) were successfully isolated. Mean duration of radiofrequency energy applications per pulmonary vein was $6.0 \pm 4.3$ minutes. Radiofrequency energy was delivered to $21 \%$ to $60 \%$ of the ostial circumference to achieve complete electrical isolation.

There was a positive correlation between ostial diameter and duration of radiofrequency energy needed to achieve complete electrical isolation $(\mathrm{r}=0.27, \mathrm{P}=0.001)$.

\section{Effects of Ablation on Ostial Diameter}

Among the 192 pulmonary veins that were targeted for isolation, mean ostial diameter was $1.5 \pm 3.2 \mathrm{~mm}(8 \% \pm 17 \%)$ smaller after segmental ostial ablation than before ablation $(\mathrm{P}<0.001$; Fig. 6).

Forty-two right inferior pulmonary veins that were not targeted for isolation were used to control for changes in technique between serial CT scans. Mean ostial diameter of these veins was $16.4 \pm 2.9 \mathrm{~mm}$ in the baseline CT scans and remained unchanged at $16.2 \pm 2.6 \mathrm{~mm}$ in follow-up CT scans $(\mathrm{P}=0.5$; Fig. 6).

In baseline CT scans, the mean distance from the ostium to the first branch of the pulmonary veins was $17.9 \pm 7.5 \mathrm{~mm}$. In follow-up CT scans, this distance was $17.5 \pm 7.7$, which did not differ significantly from baseline $(\mathrm{P}=0.1)$.

\section{Effects of Segmental Ostial Ablation on Posterior Left Atrial Area}

Mean posterior left atrial area was $83 \pm 207 \mathrm{~mm}^{2}(5 \% \pm$ $13 \%)$ smaller after ablation than before ablation $(\mathrm{P}<0.01$; Fig. 5). There was no significant correlation between the changes in ostial diameter and posterior left atrial area after segmental ostial ablation $(\mathrm{r}=0.05, \mathrm{P}=0.4)$.

\section{Focal Pulmonary Vein Narrowing}

Focal narrowing of a pulmonary vein was observed in $6(3 \%)$ of the 192 pulmonary veins that underwent segmental ostial ablation. Mean amount of focal narrowing was $7.3 \pm$ $1.8 \mathrm{~mm}(44 \% \pm 11 \%$, range $28 \%-61 \%)$. Focal narrowing was present at a mean of $7.6 \pm 2.2 \mathrm{~mm}$ from the ostium. Among the 6 pulmonary veins that had a focal narrowing, $2(33 \%)$ occurred in a left superior pulmonary vein and $4(67 \%)$ occurred in a left inferior pulmonary vein (Fig. 3).

Among the clinical variables of age, gender, presence of structural heart disease, ostial size prior to ablation, and duration of radiofrequency energy application, there were no predictors of focal narrowing after ablation.

At a mean follow-up of $245 \pm 105$ days after segmental ostial ablation, none of the patients had any symptoms attributable to pulmonary vein stenosis or pulmonary venous hypertension.

\section{Discussion}

\section{Main Findings}

The results of this study demonstrate that segmental ablation of the pulmonary vein ostium was associated with a $1.5 \pm 3.2 \mathrm{~mm}$ reduction in ostial diameter, representing a change of $8 \%$. This reduction in ostial diameter was not attributable to a decrease in left atrial size after elimination of atrial fibrillation. A focal pulmonary vein narrowing of $28 \%$ to $61 \%$ occurred in $3 \%$ of veins that underwent segmental isolation, and the locations of these stenoses indicated that 


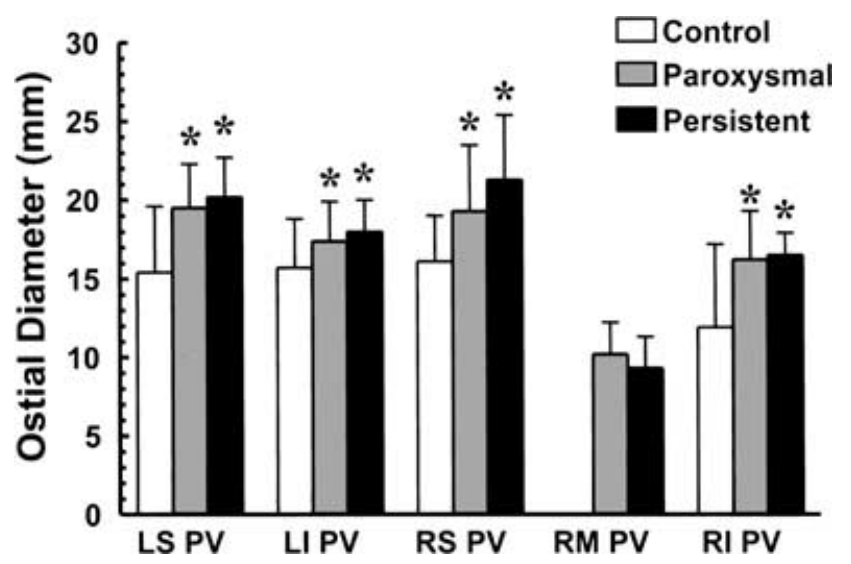

Figure 4. Mean ostial diameter of the pulmonary veins in patients with paroxysmal and persistent atrial fibrillation, and in control subjects. $* P<$ 0.01 versus control subjects. $R M=$ right middle lobe. Other abbreviations as in Figure 1.

they probably were caused by applications of radiofrequency energy delivered inside the veins instead of at the ostia. However, with the technique for segmental ostial ablation used in this study, the risk of pulmonary vein stenosis was low, and none of the patients developed any symptoms attributable to pulmonary vein stenosis.

\section{Anatomy of the Pulmonary Veins}

CT scan demonstrated that $81 \%$ of patients had 4 separate pulmonary vein ostia, $3 \%$ had 3 pulmonary vein ostia, and $16 \%$ had 5 pulmonary vein ostia. Two prior studies reported that the number of pulmonary vein ostia could be variable,,$^{3,4}$ but the sample sizes in these studies were small and the prevalence of anatomic variants could not be accurately estimated. The common occurrence of variant anatomic arrangements of the pulmonary veins demonstrates the utility of CT or magnetic resonance imaging to view the pulmonary veins before isolation procedures.

In this study, the superior pulmonary veins were found to be larger than the inferior pulmonary veins. This is consistent with the results of prior anatomic and angiographic studies. $^{3,4,12}$

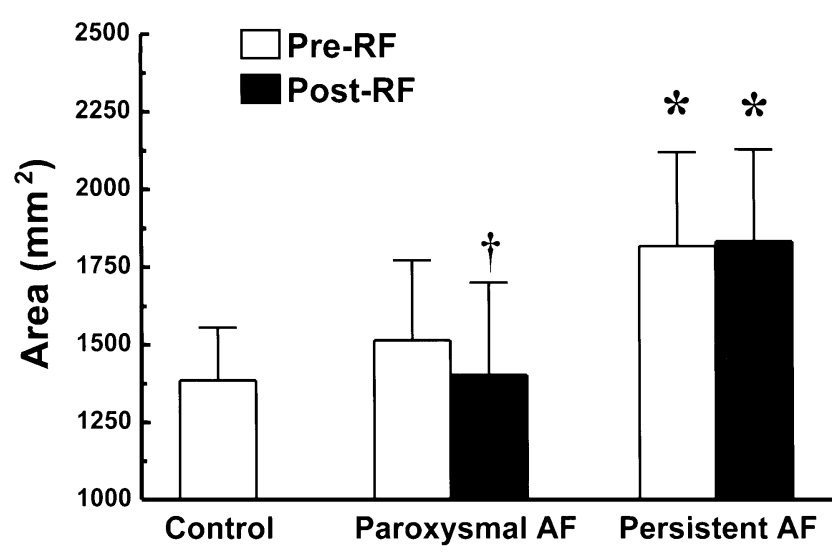

Figure 5. Posterior left atrial area in patients with atrial fibrillation before and after pulmonary vein isolation, and in control subjects. $* P<0.05$ versus controls; $\dagger P<0.05$ versus before isolation. $A F=$ : atrial fibrillation; $R F=$ radiofrequency catheter ablation.

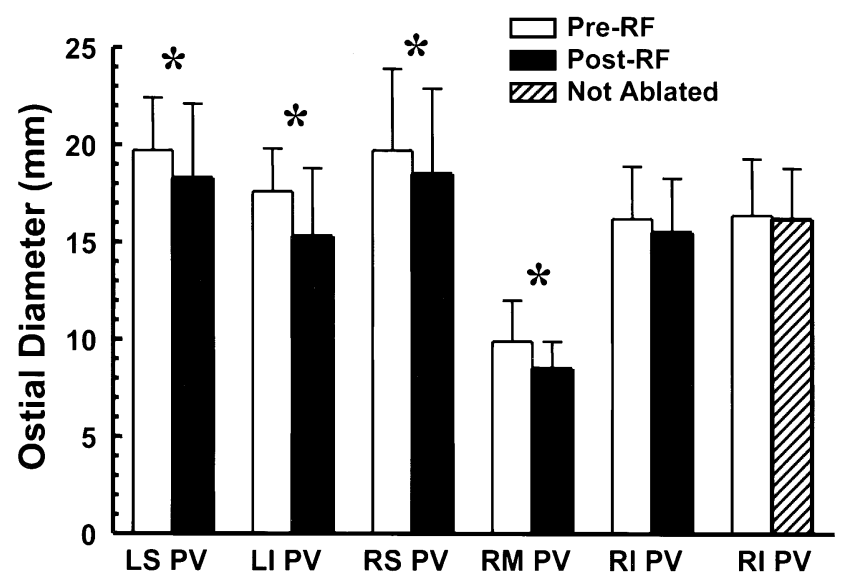

Figure 6. Effect of segmental ostial ablation on ostial diameter. Mean ostial diameter of the right pulmonary veins that were not targeted for ablation is shown at baseline (open bars) and during follow-up (hatched bars). RM= right middle lobe. Other abbreviations as in Figure 1. $* P<0.01$.

\section{Pulmonary Vein Remodeling in Atrial Fibrillation}

Both in this study and a prior study that used magnetic resonance imaging, ${ }^{13}$ patients with persistent and paroxysmal atrial fibrillation were found to have larger pulmonary veins than control subjects. Patients with paroxysmal atrial fibrillation did not have larger left atria than control subjects, suggesting that atrial fibrillation may result in anatomic remodeling of the pulmonary veins. Alternatively, patients who have intrinsically larger pulmonary veins may be more likely to develop atrial fibrillation.

\section{Effects of Segmental Ostial Ablation}

Although prior studies in which patients with atrial fibrillation underwent segmental ostial ablation of the pulmonary veins already demonstrated that symptomatic pulmonary vein stenosis is an uncommon complication, no prior studies have systematically quantitated the effects of ostial ablation on the pulmonary veins. ${ }^{5,6}$ The findings of this study demonstrate a small but statistically significant reduction in ostial diameter. Therefore, even when applications of radiofrequency energy are limited to $35 \mathrm{~W}$ and an electrode-tissue interface temperature of $52^{\circ} \mathrm{C}$, and even when they are limited to the ostium, a small degree of ostial narrowing can be expected.

There was a focal narrowing within the left superior or left inferior pulmonary vein in $3 \%$ of isolated veins. Focal narrowing was most prevalent in the left inferior pulmonary vein, probably because this vein has a more medial location within the cardiac silhouette, leading to less precise identification of the ostium and a higher probability of delivery of radiofrequency energy within the pulmonary vein.

The largest degree of focal narrowing was $61 \%$, which would translate to a $36 \%$ reduction in cross-sectional area. This degree of focal narrowing is not enough to limit flow, thus explaining why none of the patients in this study developed any symptoms attributable to pulmonary vein stenosis.

\section{Accuracy of Serial Measurements}

Several possible sources of variability in the measurement of pulmonary vein dimensions in this study include imprecise identification of the pulmonary vein ostium; variability in the placement of digital calipers in the same plane before and after ablation; motion artifact; inadequate visualization due to 
overlying structures; and the inherent resolution of CT scans. However, the temporal changes in ostial diameter found in the present study are validated by the finding that there was no change in the mean ostial diameter of pulmonary veins that were not targeted for ablation. Furthermore, the distance from the ostium to the first branch point, which should not be affected by ostial ablation, also was found to be unchanged after segmental ostial ablation.

\section{Study Limitations}

A limitation of this study is that postablation CT scans were not repeated 6 to 12 months after the catheter ablation procedures. Therefore, the possibility of progressive pulmonary vein narrowing more than 4 months after ablation cannot be ruled out.

Another limitation is that the resolution of the CT scans was $1.25 \mathrm{~mm}$, which is equal to approximately $7 \%$ of the ostial diameter of an average pulmonary vein. Mean percentage change in ostial diameter after segmental ostial ablation was $8 \%$. Therefore, the changes in ostial diameter detected in this study were at the limits of resolution of the imaging technique.

\section{Conclusion}

Imaging of the pulmonary veins by CT may facilitate pulmonary vein isolation procedures by identifying anatomic variations of the pulmonary veins in approximately $20 \%$ of patients. Although a significant degree of ostial narrowing occurs after segmental ostial ablation, the mean degree of narrowing is less than $10 \%$. A focal stenosis may occur when radiofrequency energy is applied inside a vein instead of at the ostium. However, symptomatic pulmonary vein stenosis is rare, at least with the conventional radiofrequency ablation technique used in this study.

\section{References}

1. Haissaguerre M, Jais P, Shah DC, Takahashi A, Hocini M, Quiniou G, Garrigue S, Le Mouroux A, Le Metayer P, Clementy J: Spontaneous initiation of atrial fibrillation by ectopic beats originating in the pulmonary veins. N Engl J Med 1998;339:659-666.

2. Chen SA, Hsieh MH, Tai CT, Tsai CF, Prakash VS, Yu WC, Hsu TL, Ding YA, Chang MS: Initiation of atrial fibrillation by ectopic beats originating from the pulmonary veins: Electrophysiological characteristics, pharmacological responses, and effects of radiofrequency ablation. Circulation 1999;100:1879-1886.

3. Nathan H, Eliakim M: The junction between the left atrium and the pulmonary veins: An anatomic study of human hearts. Circulation 1966;34:412-422.

4. Ho SY, Sanchez-Quintana D, Cabrera JA, Anderson RH: Anatomy of the left atrium: Implications for radiofrequency ablation of atrial fibrillation. J Cardiovasc Electrophysiol 1999;10:1525-1533.

5. Haissaguerre M, Shah DC, Jais P, Hocini M, Yamane T, Deisenhofer I, Chauvin M, Garrigue S, Clementy J: Electrophysiological breakthroughs from the left atrium to the pulmonary veins. Circulation 2000; 102:2463-2465.

6. Oral H, Knight BP, Tada H, Ozaydin M, Chugh A, Hassan S, Scharf C, Lai SW, Greenstein R, Pelosi F, Jr., Strickberger SA, Morady F: Pulmonary vein isolation for paroxysmal and persistent atrial fibrillation. Circulation 2002;105:1077-1081.

7. Robbins IM, Colvin EV, Doyle TP, Kemp WE, Loyd JE, McMahon WS, Kay GN: Pulmonary vein stenosis after catheter ablation of atrial fibrillation. Circulation 1998;98:1769-1775.

8. Scanavacca MI, Kajita LJ, Vieira M, Sosa EA: Pulmonary vein stenosis complicating catheter ablation of focal atrial fibrillation. J Cardiovasc Electrophysiol 2000;11:677-681.

9. Haissaguerre M, Jais P, Shah DC, Garrigue S, Takahashi A, Lavergne T, Hocini M, Peng JT, Roudaut R, Clementy J: Electrophysiological end point for catheter ablation of atrial fibrillation initiated from multiple pulmonary venous foci. Circulation 2000;101:14091417.

10. Yu WC, Hsu TL, Tai CT, Tsai CF, Hsieh MH, Lin WS, Lin YK, Tsao HM, Ding YA, Chang MS, Chen SA: Acquired pulmonary vein stenosis after radiofrequency catheter ablation of paroxysmal atrial fibrillation. J Cardiovasc Electrophysiol 2001;12:887-892.

11. Seshadri N, Novaro GM, Prieto L, White RD, Natale A, Grimm RA, Stewart WJ: Pulmonary vein stenosis after catheter ablation of atrial arrhythmias. Circulation 2002;105:2571-2572.

12. Lin WS, Prakash VS, Tai CT, Hsieh MH, Tsai CF, Yu WC, Lin YK, Ding YA, Chang MS, Chen SA: Pulmonary vein morphology in patients with paroxysmal atrial fibrillation initiated by ectopic beats originating from the pulmonary veins: Implications for catheter ablation. Circulation 2000;101:1274-1281.

13. Tsao HM, Yu WC, Cheng HC, Wu MH, Tai CT, Lin WS, Ding YA, Chang MS, Chen SA: Pulmonary vein dilation in patients with atrial fibrillation: Detection by magnetic resonance imaging. J Cardiovasc Electrophysiol 2001;12:809-813. 